\title{
The Application of Syntactic Priming in Second Language Research
}

\author{
Ahmad Ameri-Golestan \\ Department of English, Majlesi Branch, Islamic Azad University, Isfahan, Iran \\ Email: a.ameri@iaumajlesi.ac.ir \\ Marzieh Nezakat-Alhossaini \\ Department of English, University of Isfahan, Isfahan, Iran
}

\begin{abstract}
In this report, we provide a brief discussion of syntactic priming and how this methodology has provided insight into issues of syntactic representation, specifically in terms of the autonomy of syntax and the relationship between production and perception in syntactic representation. We present results from studies related to syntactic priming in bilinguals and second/foreign language learners that focus on the ways in which syntactic priming can illuminate the representation of syntax in acquisition and bilingual grammar. Finally, we suggest further paths of research using this methodology.
\end{abstract}

Index Terms — syntactic priming, second language research, L2 learners, L2 syntax

\section{INTRODUCTION}

One of the most difficult issues in language research is trying to determine what occurs when an individual is processing a second language. This question is related to the nature of representations the learner draws upon and also the way in which incoming information is integrated into these representations. Syntactic priming, as a research methodology, has been employed in order to deal with such issues since the mid 1980s. Syntactic priming occurs when a speaker produces a structure they have recently heard, and is defined as the tendency to produce a particular structure a speaker has encountered in their recent discourse, as opposed to an alternative structure (McDonough \& Mackey, 2008); similarly, syntactic priming can be defined as a proposal that processing a specific syntactic structure will affect the subsequent processing of the same or related syntactic structure (Branigan, Pickering, Liversedge, Stewart, \& Urbach, 1995) and may happen when repeating syntactic structures across unrelated sentences (Bock, 1986; Branigan, 2007). Priming effects may be interpersonal, that is, a speaker may repeat a structure they heard someone else use or else they may be intrapersonal, which occurs when a speaker repeats a structure they have already used.

Syntactic priming is both a mechanism and a method. As a method, it can be used to address theoretical questions in linguistics and psycholinguistics, such as, the representation of language as well as language comprehension and production (Bock, Dell, Chang, \& Onishi, 2007). As a mechanism, it has to do with mechanisms of learning that are relevant to first language acquisition and production, especially in terms of the residual activation of syntactic representation (Branigan, 2007).

After the discovery of syntactic priming (also called structural persistence and structural priming), there have been numerous studies across a wide variety of populations. Syntactic priming has been the focus of studies with children (e.g. Garrod \& Clark, 1993), aphasiacs (e.g. Saffran \& Martin, 1997), bilinguals (e.g. Bernolet, Hartsuiker, \& Pickering, 2007; Schoonbaert, Hartsuiker, \& Pickering, 2007), and second/foreign language learners (e.g. Gries \& Wulff, 2005; Kim \& McDonough, 2008; McDonough, 2006).

\section{NAtive Language Syntactic PRiMing}

Bock (1986) was the first study which specifically applied structural priming to investigate the process and representation of language. In her study, speakers repeated prime sentences (transitive and dative structures) and afterwards they described target pictures which were semantically unrelated to one another. The results showed that speakers tended to use an active description of the target picture after an active prime structure and a passive description after a passive prime structure. This also happened with dative sentences.

Bock's (1986) investigation of syntactic priming has stimulated numerous scholars to answer a variety of questions related to the implications of syntactic priming. In a paper reviewing the most important studies on syntactic (or structural) priming, Pickering and Ferreira (2008) reported studies which used syntactic priming to provide evidence for autonomous syntax indicating that the production of a sentence largely depends on an abstract syntactic form which can be defined in terms of part of speech forms and phrasal constituents organized from these and they believed that this abstract syntactic form has a large impact on syntactic priming. 
Another line of research stimulated by earlier studies of syntactic priming has concerned the question of (implicit) learning. In fact, recent research has examined syntactic priming as possibly facilitating implicit learning. Seger (1994) defined implicit learning as involving knowledge which is not accessible to consciousness; implicit learning is, to some extent, complex and abstract; it incidentally happens as some tasks are being performed, and finally, it is preserved in cases of amnesia (Bock \& Griffin, 2000). Bock and Griffin (2000) believed that all these four characteristics can be attributed to syntactic priming as facilitating implicit learning.

Conflicting results have emerged from this body of research. On the one hand, the results from certain studies suggested that syntactic priming effects, used in language production, are quite short-lived (Branigan, Pickering, \& Cleland, 1999). Although they demonstrated syntactic priming in written production, they could not find any evidence for the durability of syntactic priming. This rapid decay happened when other structures intervened between the prime and target. They presented that reliable priming occurred in situations when the target immediately followed the prime. In other words, priming between consecutive completions is not likely to be affected by earlier completion.

On the other hand, Bock and Griffin (2000) came to the conclusion that priming does result in implicit learning. The authors defined implicit learning as the automatic non-deliberative character of structural representation, its abstractness, and its persistence over time. They investigated the issue to see whether syntactic priming leads to implicit learning. In their experiments (Experiment 1: priming over short lags, that is, two intervening sentences; and Experiment 2: priming over longer lags, that is, 10 intervening sentences), they demonstrated priming effects. Specifically their results showed that syntactic priming can persist over short and long filled intervals because other utterances which were produced during these intervals suggested that syntactic priming would not easily be disrupted by general interference from other events. (see also Bock \& Kroch, 1989; Hartsuiker \& Kolk, 1998; Weiner \& Labov, 1983 for studies of persistence of priming).

Bock and Griffin (2000) pointed out although lexical repetition enhances structural repetition, it is not essential to it. That is because there are two different factors at work. First, the activation of specific words in memory supports the subsequent activation of a recently used structure, creating structural repetition. Furthermore, when sentences are generated from non-verbal message representation, messages produced in any of the two alternative ways tend to be formulated in terms of primed procedures, reflecting structural priming.

An important question that might come up at this stage is what the authors mean by "learning." Bock and Griffin (2000) interpreted their results as "learning to talk" rather than "learning language." They pointed out that the results obtained from the two studies suggested that syntactic priming occur within a system specialized for learning how to produce sequences of words. They believed that this kind of learning is the consequence of the learning processes themselves (pp. 188-189).

\section{SECOND LANGUage LEARNER AND Syntactic PRIMING}

In addition to the investigation of syntactic priming among native language speakers, numerous studies have also been conducted on syntactic priming among second language learners (bilinguals, second/foreign language learners). Different aspects of these language users were examined, in terms of representation, comprehension, and production.

One of the most important issues that have concerned second language/bilingual researchers is the representation of the two languages in the bilinguals' brain/mind. Are the two languages integrated/shared or separate among bilinguals? That is, if the two languages are shared, the bilingual has a single store for the two languages, and if the two languages are separate, the bilingual has separate stores for them (Hartsuiker, Pickering, \& Veltkamp, 2004). Hartsuiker et al. (2004) pointed out that although much research has been conducted investigating this question in terms of the representation of words or concepts (e.g., Kroll \& Stewart, 1994; McElree, Jia, \& Litvak, 2000), little has been done on whether other aspects of language (e.g., syntax) are shared or separate (see also Hartsuiker \& Pickering, 2008). Hartsuiker et al. (2004) investigated the question of whether syntax is separate or shared among Spanish-English bilinguals. They tested the shared-syntax account taking into consideration the evidence from syntactic priming. They believed that if syntax is shared between the two languages, it would predict cross-linguistic syntactic priming. Using a picture description task which contained active/passive constructions and the confederates in order to collect the data, Hartsuiker et al. (2004) came to the conclusion that the experiment showed cross-linguistic syntactic priming in dialogue. They reported that Spanish-English bilinguals produced English passive sentences more often after a Spanish passive sentence than after a Spanish intransitive or active sentence. They pointed that the results demonstrated crosslinguistic syntactic priming between production and comprehension in the context of interactive language use between the languages that are moderately related.

McDonough (2006), in line with previous research on interaction studies, explored whether syntactic priming plays a role in L2 development through interaction. She tried to answer two research questions. Does syntactic priming occur during interaction between L2 English speakers, and whether English L2 speakers show increased use of the target structure following exposure to the confederate's primes? In order to answer her research questions, she used a picture description task and dative alternation as the target structure. Furthermore, to increase the authenticity of interaction among the participants, she used the 'modified confederate scripting technique' (Branigan, Pickering, \& Cleland, 2000). Here, confederates are advanced language learners or research assistants who participate in picture description sessions 
instead of the researcher. They have the same pictures as the participants, but their pictures are scripted for the prime only.

In order to answer the questions, McDonough (2006) conducted two experiments. The results of the first experiment showed that the interaction between these ESL speakers (the L2 learner participants and the confederates) showed evidence of syntactic priming for prepositional datives, but not for double object datives. She believed that one reason why syntactic priming was not effective for the double object construction could be because these ESL learners had not learned the complex semantic and morphological rules required for the production of the double object datives. To explain the results, McDonough (2006) pointed out that previous research which adopted a usage-based approach (Bley-Vroman \& Yoshinaga, 1992; Inagaki, 1997), where development starts with formulaic expression and proceeds to a limited scope pattern, and eventually to abstract representations (Tomasello, 2000), has shown that second language learners are not sensitive to all of the narrow-range rules (Pinker, 1989). Therefore, it can be inferred that these second language learners resort to an item-based learning where they are more sensitive to the number of times a particular verb appears in the double object dative form (McDonough, 2006, p. 193). She believed that her participants could not have mastered the abstract representation yet; consequently, their production of double object datives was limited to specific lexical items.

In order to answer the second research question, McDonough (2006) conducted a second experiment in which she used the same procedure as in the first experiment, except for the target structure. Although the target structure was, like the first experiment, dative alternation, she only used double-object datives as primes. The results of the second experiment showed that the interaction between the interlocutors showed no evidence of syntactic priming. The experiment showed that the participants tended to use significantly more prepositional datives than double object datives. It seems that exposure to the confederates and being provided with primes (double object datives) had no significant effect on their subsequent production.

Kim and McDonough (2008) examined the impact of syntactic priming on Korean EFL learners' production of passive sentences. Taking EFL proficiency into account, they explored the question of whether syntactically primed passives would result in increased production of such structures among their Korean EFL participants. The participants, divided into three proficiency groups, took part in individually held picture description sessions. The results indicated that all three proficiency groups produced significantly more passives when primed by the researcher. However, the difference for the low group was more significant than for the middle and high groups, which could be because the impact of individual lexical items was greater for those learners, which is in line with previous research in L1 (Pickering \& Branigan, 1998). Kim and McDonough (2008) explained that these learners are more dependent on individual lexical items compared with advanced learners.

Ameri-Golestan (2010) investigated syntactic priming effects on Persian speaking L2 learners of English production of indirect questions/requests. In Experiment 1, which intended to see whether priming facilitates the subsequent use of the target structure, the participants took part in individually held picture description sessions. The results showed that syntactic priming was effective and, actually, increased the likelihood of subsequently producing indirect questions/requests among the participants. In Experiment2, which dealt with the impact of syntactic priming on modality transfer, the participants were asked to provide a written description of the pictures they had described in the previous session. The results indicated that the participants of the high-proficiency group outperformed those of the mid-proficiency and control groups in transferring syntactic priming effects from one skill to another. He pointed out that one important explanation for such results could be presented in terms of inverse-preference effects (Pickering \& Ferreira, 2008) according to which structures that are less preferred (indirect questions/requests among Persianspeaking EFL learners) seem to exhibit higher syntactic priming. They believed that these effects could be because of the way speakers process prime structures, or the way they process target structures (see also Hartsuiker \& Kolk, 1998; Hartsuiker, Kolk, \& Huiskamp, 1999; Scheepers, 2003).

\section{The Relevance OF Syntactic Priming FOR L2 SyntaX}

But what does all this mean for L2/bilingual syntax? The most important contribution of syntactic priming studies to L2 syntax is that such studies tap into mental representation of language in a bilingual mind: whether it is shared or separate. That is, when the bilingual is primed for a particular structure in one language, they tend to use the same type of structure in the other. For example, Spanish-English bilingual participants of Hartsuiker et al.'s (2004) experiment, who had been primed by Spanish passives, tended to use a passive structure when describing a picture in English.

We also agree with Pickering and Ferreira (2008) who believed that syntactic priming is informing linguistic theory. Not only syntactic priming studies have investigated the representation of language in adult monolingual native speakers, it can also help determine the linguistic systems of other populations as well; such as, children, second language learners, bilinguals, and aphasiacs. Particularly, cross-linguistic priming is especially seen as informative about the extent to which structures in different languages should be analyzed in the same way.

\section{CRITIQUE}


Syntactic priming, like any other research methodology, is not without any criticism. An important critique that can be leveled at syntactic priming studies is that of scope. Most syntactic priming studies have dealt with a limited number of structures among a variety of populations. For example, while numerous studies have focused on dative alternation (double-object vs. prepositional object) and passives, very few studies have examined other structures.

Another criticism that can be put forward is that syntactic priming effects might be semantic rather than syntactic or structural, and that speakers may repeat abstract aspects of semantic structure (Garrod \& Anderson, 1987). Furthermore, Bock, Loebell, and Morey (1992) showed that the semantic features which are assigned to a specific position in the sentence (when an animate is the subject, for example) seem to play some role in syntactic priming.

Some other studies have shown that syntactic priming effects might be lexical rather than syntactic. For example, Kim and McDonough (2008) pointed out that their results can be interpreted in terms of the impact of individual lexical items. That is, the fact that their participants produced more passives when primed by that particular structure was because of the difference in the impact of individual lexical items among the proficiency groups. That is, the less proficient the learner, the more they depended on individual lexical items. This interpretation questions the conclusion that syntactic priming played any role in the results they obtained with low-proficiency group.

Furthermore, there is a possibility that syntactic priming is strategic. That is, people deliberately choose to use the same syntax as another speaker, perhaps to make the other speaker feel positively towards them (Branigan, p.c.).

\section{FURTHER RESEARCH}

It seems obvious that syntactic priming studies are new to the investigation of language studies both L1 and, particularly, L2. There are numerous directions to further research using priming as an alternative research methodology. One of the most interesting and promising areas of L2 syntactic priming research is the representation of language, considering the role language proficiency plays into account. One of these issues is cross-linguistic syntactic integration (De Bot, 1992; Ullman, 2001), that is, to what extent the two languages are separate. This question can further be investigated using syntactic priming methodology. Different structures can be used, especially those which are different between languages and usually learners have problems with.

One of the most important problems with studies which have been conducted on syntactic priming is that they use a very limited number of structures. For example, so many studies have investigated double-object vs. prepositional object priming, and some studies have dealt with active vs. passive priming and noun phrases. It seems that much more structures can be dealt with using syntactic priming as a research methodology; such as, indirect speech, relative clauses, wh-questions, tag questions, etc.

Another important line of research can be the investigation of classroom context. Syntactic priming can be used as a research methodology to investigate classroom interaction, that is, learner-learner interaction as well as teacher-learner interaction. For example, in order to present grammar points using more traditional methodology, they can be primed. The teacher can prime the structure and then encourage the students to use that particular structure in their two-by-two interaction and classroom activities.

\section{CONCLUSION}

This study intended to present a 'short report' on some of the studies that have been conducted on syntactic priming as a research methodology which investigated different aspects of language acquisition in terms of representation, comprehension, and production. Our main purpose in this paper is to encourage researchers to consider syntactic priming as an alternative research methodology. We believe that the issues we introduced in this report are worth contemplating, and considering for further research; lots of studies can be done to investigate the representation of language among bilinguals to see whether the two languages are shared or separate, considering a variety of languages, participants, and tasks. Furthermore, the role language proficiency plays in the process of second language acquisition and EFL/ESL classroom context can be investigated by syntactic priming as a research methodology.

\section{ACKNOWLEDGEMENT}

We would like to thank Prof. Holly Branigan, Prof. Martin Pickering, Prof. Robert Hartsuiker, and Dr. Christine Shea for their helpful comments on different parts of this manuscript.

\section{REFERENCES}

[1] Ameri-Golestan, A. (2010). The impact of syntactic priming on Persian speaking EFL learners' production of indirect questions/requests. PhD Dissertation, Khorasgan Azad University: Isfahan.

[2] Bernolet, S., R. J. Hartsuiker, \& M. J. Pickering. (2007). Shared Syntactic Representations in Bilinguals: Evidence for the Role of Word-Order Repetition. Journal of Experimental Psychology: Learning, Memory, and Cognition 33, 931-949.

[3] Bley-Vroman, R. \& N. Yoshinaga. (1992). Broad and Narrow Constraints in the English Dative Alternation: Some Fundamental Differences between Native Speakers and Foreign Language Learners. University of Hawai'i Working Papers in ESL 11, 157-199.

[4] Bock, K. (1986). Syntactic Persistence in Language Production. Cognitive Psychology 18, 355-87. 
[5] Bock, K., G. S. Dell, F. Chang, \& K. H. Onishi. (2007). Persistent Structural Priming from Language Comprehension to Language Production. Cognition 104. 437-458.

[6] Bock, K. \& Z. M. Griffin. (2000). The Persistence of Structural Priming: Transient Activation or Implicit Learning? Journal of Experimental Psychology: General 1292, 177-92.

[7] Bock, K. \& A. S. Kroch. (1989). The Isolability of Syntactic Processing. In Carlson, G. N. \& M. K. Tanenhaus, (eds.), Linguistic structures in language processing. Dordrecht: Kluwer, 157-196.

[8] Bock, K., H. Loebell, \& R. Morey. (1992). From Conceptual Roles to Structural Relations: Bridging the Syntactic Cleft. Psychological Review 99, 150-171.

[9] Branigan, H. (2007). Syntactic Priming. Language and Linguistics Compass 1, 1-16.

[10] Branigan, H., M. J. Pickering, \& A. A. Cleland. (1999). Syntactic Priming in Written Production: Evidence for Rapid Decay. Psychonomic Bulletin and Review 6, 535-40.

[11] Branigan, H., M. J. Pickering, \& A. A. Cleland. (2000). Syntactic co-ordination in dialogue. Cognition 75, B13-B25.

[12] Branigan, H., M. J. Pickering, S. P. Liversedge, A. J. Stewart, \& T. P. Urbach. (1995). Syntactic Priming: Investigating the Mental Representation of Language. Journal of Psycholinguistic Research 24, 489-506.

[13] De Bot, K. (1992). A Bilingual Production Model: Levelt's 'Speaking' model adapted. Applied Linguistics 41, 365-397.

[14] Garrod, S. \& A. Anderson. (1987). Saying What You Mean in Dialogue: A Study in Conceptual and Semantic Co-ordination. Cognition 27, 737-767.

[15] Garrod, S. \& A. Clark. (1993). The Development of Dialogue Co-ordination Skills in Schoolchildren. Language and Cognitive Processes 8, 101-126.

[16] Gries, S. T. \& S. Wulff. (2005). Do Foreign Language Learners Also Have Constructions? Annual Review of Cognitive Linguistics 3, 182-200.

[17] Hartsuiker, R. J. \& H. H. J. Kolk. (1998). Syntactic Persistence in Dutch. Language and Speech 41, 143-184.

[18] Hartsuiker, R. J., H. H. J. Kolk, \& P. Huiskamp. (1999). Priming Word Order in Sentence Production. Quarterly Journal of Experimental Psychology 52A, 129-147.

[19] Hartsuiker, R. J. \& M. J. Pickering. (2008). Language Integration in Bilingual Sentence Production. Acta Psychologica, 128, 479-489.

[20] Hartsuiker, R. J., M. J. Pickering, \& E. Veltkamp. (2004). Is Syntax Shared or Separate between Languages? Cross-linguistic Syntactic Priming in Spanish-English Bilinguals. Psychological Science 15, 409-414.

[21] Inagaki, S. (1997). Japanese and Chinese Learners' Acquisition of the Narrow-Range Rules for the Dative Alternation in English. Language Learning, 47, 637-669.

[22] Kim, Y. \& K. McDonough. (2008). Learners' Production of Passives During Syntactic Priming Activities. Applied Linguistics $29 / 1,149-154$

[23] Kroll, J. F. \& E. Stewart. (1994). Category and Interference in Translation and Picture Naming: Evidence for Asymmetric Connections Between Bilingual Memory Representations. Journal of Memory and Language 33, 149-174.

[24] Loebell, H. \& K. Bock. (2003). Structural Priming Across Languages. Linguistics 41, 791-824.

[25] McDonough, K. (2006). Interaction and Syntactic Priming: English L2 Speakers' Production of Dative Constructions. Studies in Second Language Acquisition 28, 179-207.

[26] McDonough, K. \& A. Mackey. (2008). Syntactic Priming and ESL Question Development. Studies in Second Language Acquisition 30, 31-47.

[27] McElree, B., G. Jia, \& A. Litvak. (2000). The Time Course of Conceptual Processing in Three Bilingual Populations. Journal of Memory and Language 42, 229-254.

[28] Pickering, M. J. \& H. Branigan. (1998). The Representation of Verbs: Evidence from Syntactic Priming in Language Production. Journal of Memory and Language 39, 633-651.

[29] Pickering, M. J. \& V. S. Ferreira. (2008). Structural priming: A critical review. Psychological Review 134 (3), $427-459$.

[30] Pinker, S. (1989). Learnability and Cognition: The Acquisition of Argument Structure. Cambridge, MA: MIT Press.

[31] Saffran, E. M. \& N. Martin. (1997). Effects of Structural Priming on Sentence Production in Aphasics. Language and Cognitive Processes 12, 877-882.

[32] Scheepers, C. (2003). Syntactic Priming of Relative Clause Attachments: Persistence of Structural Configuration in sentence production. Cognition 89, 179-205.

[33] Schoonbaert, S., R. J. Hartsuiker, \& M. J. Pickering. (2007). The Representation of Lexical and Syntactic Information in Bilinguals: Evidence from Syntactic Priming. Journal of Memory and Language 56, 153-171.

[34] Seger, C. A. (1994). Implicit Learning. Psychological Bulletin 115, 163-196.

[35] Tomasello, M. (2000). Do Young Children Have Adult Syntactic Competence? Cognition 74, 209-253.

[36] Ullman, T. (2001). The Neural Basis of Lexicon and Grammar in First and Second Language: The Declarative/Procedural Model. Bilingualism: Language and Cognition 4, 105-122.

[37] Weiner, E. J. \& W. Labov. (1983). Constraints on the Agentless Passive. Journal of Linguistics 19, 29-58.

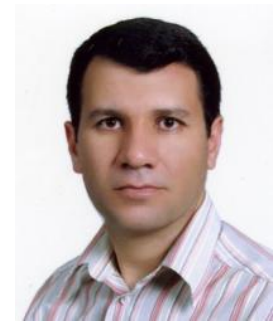

Ahmad Ameri-Golestan, born in Isfahan, Iran, obtained his $\mathrm{PhD}$ in Teaching English as Foreign Language from Khorasgan Azad University, Isfahan, in 2010.

He currently works as the HEAD OF ENGLISH DEPARTMEN at Islamic Azad University- Majlesi Branch, Isfahan. His academic papers are published in national and international journals. He has also presented papers in national and international conferences, such as the Second International IDEA Conference, Ankara, Turkey, 2007 and the $7^{\text {th }}$ International TELLSI conference, Yazd, Iran. He has also published an ESP textbook: English for Students of Medicine (second edition) (Tehran, SAMT publications, 2011). His main research interests are syntactic priming and second language acquisition research.

Dr. Ameri is currently a member of TELLSI (Teachers of English Language and Literature Society of Iran). 


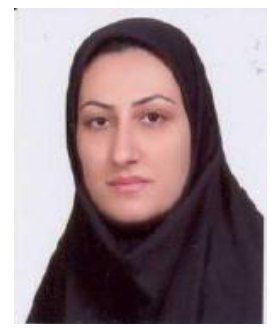

Marzieh Nezakat-Alhossaini, born in Isfahan, Iran, obtained her MA in Teaching English as Foreign Language from Islamic Azad University -Najafabad Branch, Isfahan, in 2007. She is a PhD candidate of TEFL at University of Isfahan.

She currently works as an instructor in Isfahan University of Medical Sciences, Isfahan. She has also presented papers in national and international conferences, such as the Second International IDEA Conference, Ankara, Turkey, 2007 and the $4^{\text {th }}$ and the $7^{\text {th }}$ International TELLSI conferences, Shiraz and Yazd, Iran. Her main research interests are syntactic priming and second language acquisition research.

Ms. Nezakat is currently a member of TELLSI (Teachers of English Language and Literature Society of Iran). 